\title{
Resistance Exercise Program for the Elderly and Its Effect on Depression, Stress, and Autonomic Balance
}

\author{
Kim Won Jong ${ }^{1}$, Kim Jung Kyung ${ }^{2}$, and Lee Jung Geun ${ }^{3 *}$ \\ ${ }^{1}$ College of Nursing, Eulji University, Korea \\ ${ }^{2}$ Department of Nursing, Gimcheon University, Korea \\ ${ }^{3}$ Department of Nursing, kongju University, Korea \\ ${ }^{1}$ wjtkfkd77@eulji.ac.kr, ${ }^{2} j j 2 c @$ nate.com, ${ }^{3}$ gh1511@daum.net
}

\begin{abstract}
The purpose of this study is to determine how a resistance exercise program with an elastic band affects the elderly. Elderly subjects were studied for 12 weeks to determine the program's effect on depression, stress, and autonomic balance. Methods: There were 30 subjects in the experimental group and 31 subjects in the control group. The experimental group participated in resistance exercise three times a week (Monday, Wednesday, and Friday) for 12 weeks, and the control group did not participate in resistance exercise for 12 weeks. Results: There was no significant difference between the two groups regarding the general characteristics and homogeneity of the dependent variable. There were significant differences in depression and stress, and parasympathetic activity was partially significant but sympathetic activity was not.
\end{abstract}

Keywords: Autonomic balance, Canopy9, Depression, Stress

\section{Introduction}

In Korea, social, medical, and economic problems related to the elderly are emerging as Korea enters an aging society at a rapid pace without sufficient personal or social response systems [1]. In particular, medical expenses for the elderly are increasing rapidly, and in 2017, the medical expenses for elderly people with health insurance accounted for $39.9 \%$ of the total. This is a trend that increases by $1.1 \%$ each year compared with the previous year [2]. For the elderly, complete mental and healthy physical functioning are important factors for successful aging. Therefore, among the various characteristics that appear as aging progresses, it is very important to delay declines in mental cognitive function and physical function so that they can engage in active social and physical activities [3].

Depression in the elderly is getting worse, and such a phenomenon is inevitable. In particular, stress is a major cause of depression, and such depression shows an autonomic nervous system imbalance not only in the elderly but in all people with depressive symptoms. It has been reported that the autonomic imbalance caused by depression activates the sympathetic nervous system, reduces parasympathetic activity, induces cardiovascular disease, and increases mortality [4][5][6].

The autonomic nervous system consists of the sympathetic nervous system and the parasympathetic nervous system. In general, it is known that the response to stress activates

Article history:

Received (October 6, 2020), Review Result (November 9, 2020), Accepted (December 12, 2020) 
the sympathetic nervous system and decreases the activity of the parasympathetic nervous system [7]. These two nervous systems adapt to the ever-changing environmental demands to protect the homeostasis of our body and maintain a constant balance. This is called sympathovagal balance [8].

The balance of the autonomic nervous system is divided into a high-frequency (HF) band and a low-frequency (LF) band. HF is about $0.25 \mathrm{~Hz}$ and is related to the parasympathetic nerve. LF is about $0.1 \mathrm{~Hz}$, and both the sympathetic nervous system and the parasympathetic nervous system are related. If one of these nervous systems is more dominant, autonomic imbalance occurs. This situation causes several diseases in our body. In particular, activation of the sympathetic nervous system can increase stress and strain the heart. When the parasympathetic nervous system is activated, mood disorders such as depression arise [9]. This is a severe stressful situation for the elderly and can cause serious problems such as heart disease and death by acting as a factor that causes various diseases. Therefore, efforts to remove these risk factors should be made before autonomic imbalance appears.

As one of the efforts to eliminate the imbalance of the autonomic nerve, it was said that resistance exercise controls weight and improves heart function and muscle recovery [10][11]. Looking at previous studies of the elderly, exercise alleviates depression symptoms. It has been reported to improve the vascular function of the heart by reducing stress and improving the autonomic nervous system [12][13][14][15]. There are many types of resistance exercises. Among them, exercise using a band guarantees more stability. In addition, it is easy to control the exercise intensity, and resistance exercise can be used to work all the muscles in the body, so it is widely applied at present. have. Furthermore, elastic band exercises apply force in the opposite direction of gravity, which is helpful in improving muscle mass, reducing depression, and relieving stress [11][16][17]. It also has the advantage of being independent of place, making it convenient for the elderly and effective in providing physical stability. Therefore, this study intends to confirm that a 12-week resistance exercise program with an elastic band has a positive effect on the elderly in terms of depression, stress, and autonomic balance.

\section{Body}

\subsection{Research design}

This study was a randomized controlled pre-post parallax study to determine the effects on depression, stress, and autonomic nervous system balance (sympathetic, parasympathetic) in the elderly through participation in an elastic band resistance exercise program for 12 weeks.

\subsection{Research subject selection}

The subjects were elderly people age 60 or older residing in $\mathrm{G}$ city, and were recruited as voluntary participants who were given an explanation of the study and randomly assigned to the experimental group or the control group. Concerned about the spreading effect of this study, the experimental group data were collected first, and then the control data were collected. Data collection was conducted for 12 weeks for each group from May 15, 2019 to November 13, 2019. A total of 71 subjects who met the selection criteria were randomly assigned: 36 subjects in the experimental group and 35 subjects in the control group. After collecting the participant data, the data of 30 subjects from the experimental group were analyzed (six subjects dropped out), and the data of 31 subjects from the control group were analyzed (four subjects dropped out). 


\subsection{Calculating the sample size}

To compare the effects on depression, stress, and autonomic nervous system balance (sympathetic, parasympathetic) in the elderly after participating in resistance exercise programs using elastic bands, a repeated measurement variance analysis in the G-power program (F-test) was conducted on the subjects. The median effect was 0.25 , the significance level of the two-sided test was 0.05 , the power of the test was 0.95 , the number of groups was two, the number of measurements was three, and the correlation coefficient was 0.3 . As a result, 30 samples were required per group.

\subsection{Experimental treatment}

Resistance exercise refers to a method of enhancing muscle mass by applying a load to the relevant muscle[18].-The experimental treatment in this study was conducted by applying a 12-week elastic band resistance exercise program developed for adults that complained of scapular fascia pain syndrome [17].

\subsection{Procedures}

The resistance exercise program proposed in this study was implemented as follows. TheraBand was provided to the subjects and they were allowed to exercise by referring to the produced video. The program lasted for eight weeks and three days. Each session consisted of eight different movements, and resistance exercise was implemented 15 times for each movement. In total, two sets of exercises were performed for three sessions. It took approximately $70 \mathrm{~min}$ to complete the full course of each exercise session.

The control group had a daily routine without the intervention of a resistance exercise program for 8 weeks. instructed to follow their normal daily routine for eight weeks without the intervention of the resistance exercise program. After that, we provided programs like experimental groups to those who wanted [Figure 1].

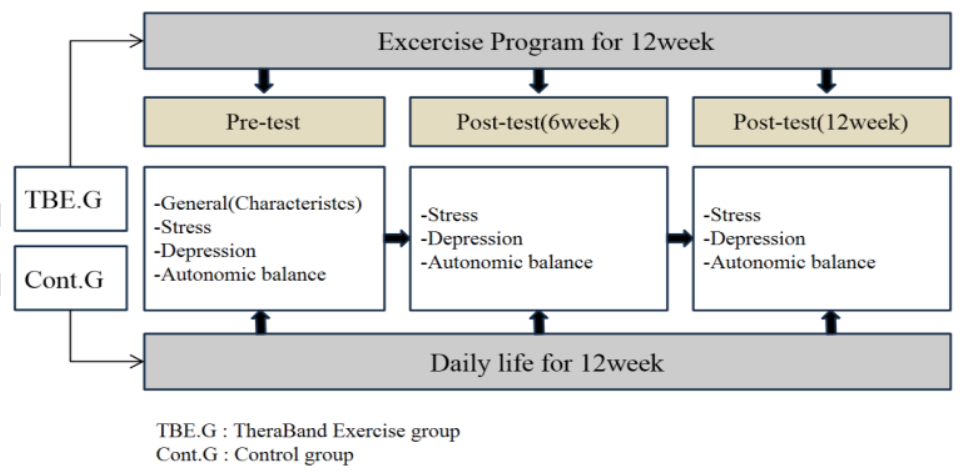

Figure 1. Process flow diagram.

\subsection{Research tools}

\subsubsection{Depression}

The depression scale was developed by Radloff in 1977 [19], and Chon et al. developed the Korean depression scale CES-D (The Center for Epidemiological Studies Depression Inventory) [20]. 


\subsubsection{Stress}

The stress scale was developed by Cohen et al. (1983) [21] and was measured by the stress scale [22] developed by Jung et al. in Korean.

\subsubsection{Autonomic nervous system balance (Canopy9)}

In order to evaluate the balance of the autonomic nervous system, the frequency domain was analyzed by continuous measurement for 5 minutes using the Canopy9 PLUS (IEMBIO) device, which analyzes heart rate variability and provides an index evaluating the balance of the autonomic nervous system by a non-invasive method. LF represents the sympathetic nerve activity in the entire autonomic nervous system in the low-frequency region, and HF represents the parasympathetic nerve activity in the high-frequency region. The higher the value of sympathetic activity and parasympathetic activity, the higher the activity is, and the stress state and resistance are evaluated according to the balance between the sympathetic and parasympathetic nerves.

\subsection{Data analysis}

The collected data were analyzed using SPSS 24.0. The homogeneity test for the general characteristics of the subjects was analyzed by frequency, percentage, mean, $\mathrm{x} 2$-test, and $\mathrm{t}$ test, and the pre-dependent variable identity test was analyzed by t-test. To verify the effectiveness of experimental intervention, the results of the experimental group and the control group were analyzed by t-test and repeated measures ANOVA. In addition, the magnitude of the effect between the independent variable and the dependent variable was suggested by analyzing the partial $\eta^{2}$ between groups and time. The value of the partial eta squared is described in the range of 0 to 1 , and the closer the value is to 1 , the larger the difference between the groups and the error is small. In general, if the partial eta squared is 0.01 , the effect is small, if it is 0.06 , the effect is medium, and if it is 0.14 or more, the effect is considered large [23].

\subsection{Ethical considerations}

The ethical considerations in conducting this research were as follows.

1) In order to recruit research subjects, a researcher visited the $G$ city health center in person, explained the purpose and content of the study, asked for consent, and voluntarily recruited subjects through bulletin boards and banners in the $\mathrm{G}$ city health center and conditional site. Before receiving the consent to participate in the study, the subject was given a sufficient explanation of the study to decide whether to participate.

2) The subject's description in the questionnaire included the procedure of the experimental treatment, the possibility of participation and withdrawal, the side effects that may occur during the experiment, the treatment methods when side effects occur, and compensation after participation.

3) The collected data were classified and processed by assigning an ID with a unique number according to the guidelines of personal information processing in order to protect the privacy of the participants.

4) Cases worth 16,000 won were provided to all subjects participating in the study at the end of data collection. 


\section{Research results}

\subsection{Verification of homogeneity of subjects' general characteristics and ethnic variables}

Among the general characteristics, the age of the subjects was $68.47 \pm 5.08$ years in the experimental group and $68.33 \pm 4.67$ years in the control group, and there was no significant difference between the two groups. As a result of testing the homogeneity of the general characteristics of the two groups, there was no significant difference in age, height, weight, level of education, exercise, and habits, indicating that the two groups were similar. Among the dependent variables, there was no significant difference in shoulder pain, depression, stress, headache, heart rate, scapular motion range, and body composition around the shoulder joint, so homogeneity was secured [Table 1].

Table 1. Homogeneity tests of general characteristics of the subjects

\begin{tabular}{|c|c|c|c|c|c|}
\hline \multirow[b]{2}{*}{ Characteristics } & \multirow[b]{2}{*}{ Category } & Exp. $(n=30)$ & Cont. $(n=31)$ & \multirow[b]{2}{*}{$X^{2}$ ort } & \multirow[b]{2}{*}{$p$} \\
\hline & & $\begin{array}{c}\text { Mean } \pm \text { SD or } \\
N(\%)\end{array}$ & $\begin{array}{c}\text { Mean } \pm \text { SD or } \\
\mathrm{N}(\%)\end{array}$ & & \\
\hline Age (yr) & & $69.23 \pm 5.26$ & $67.81 \pm 4.55$ & 1.130 & .263 \\
\hline Height $(\mathrm{cm})$ & & $157.70 \pm 5.20$ & $159.77 \pm 5.89$ & -1.456 & .151 \\
\hline $\begin{array}{l}\text { Body weight } \\
(\mathrm{kg})\end{array}$ & & $59.50 \pm 10.02$ & $59.00 \pm 9.95$ & 0.194 & .847 \\
\hline \multirow{2}{*}{ Blood pressure } & SBP & $116.07 \pm 10.68$ & $119.68 \pm 14.99$ & -1.080 & .284 \\
\hline & DBP & $72.30 \pm 8.34$ & $73.71 \pm 9.94$ & -0.600 & .551 \\
\hline \multirow[t]{2}{*}{ Education } & Less than middle & $10(33.4)$ & $14(45.1)$ & 0.494 & .623 \\
\hline & High & $14(46.6)$ & $10(32.2)$ & & \\
\hline \multirow{3}{*}{ Residence } & More than college & $6(20.0)$ & $7(22.7)$ & & \\
\hline & Family & $24(80.0)$ & $22(70.9)$ & 0.615 & .541 \\
\hline & Solitary & $6(20.0)$ & $9(29.1)$ & & \\
\hline \multirow[t]{3}{*}{$\begin{array}{c}\text { Exercise } \\
\text { (per week) }\end{array}$} & Less than one time & $4(13.3)$ & $8(25.8)$ & 1.115 & .269 \\
\hline & One to two times & $24(80.0)$ & $21(67.6)$ & & \\
\hline & More than two times & $2(6.7)$ & $2(6.6)$ & & \\
\hline Depression & & $38.46 \pm 3.46$ & $37.64 \pm 3.94$ & 0.863 & .391 \\
\hline Stress & & $36.50 \pm 3.45$ & $37.64 \pm 3.05$ & -1.035 & .304 \\
\hline \multirow{2}{*}{$\begin{array}{l}\text { Autonomic } \\
\text { balance }\end{array}$} & $\mathrm{HF}$ & $4.20 \pm 1.21$ & $4.18 \pm 0.80$ & .049 & .961 \\
\hline & $\mathrm{LF}$ & $4.12 \pm 0.87$ & $4.08 \pm 1.00$ & 0.158 & .875 \\
\hline Canopy9 & & $2.50 \pm 1.19$ & $2.48 \pm 1.17$ & 0.053 & .958 \\
\hline
\end{tabular}

Exp. = experiment group; Cont.$=$ control group

$B P S=$ Bodymetrix Pro System; NRS = numeric rating scale,; $R O M=$ range of motion.; $S D=$ standard deviation

$S B P=$ systolic blood pressure; $D B P=$ diastolic blood pressure; $L t=$ left side; $R t=$ right side

\subsection{Resistance exercise program effect on depression}

Depression was significantly different according to time as a result of repeated measurement and variance analysis of the scores measured three times for 12 weeks $(\mathrm{F}=$ $42.30, \mathrm{p}<.001)$, and there was a significant difference in the shoulder pain scores significant differences in scores between groups $(\mathrm{F}=40.88, \mathrm{p}<.001)$. In addition, there was a significant difference in the interaction between group and time $(\mathrm{F}=44.49, \mathrm{p}<.001)$. The partial eta 
squared, which is the effect of the resistance exercise program according to group and time, was 0.361 [Table 2].

Table 2. Subject comparison of depression between the experimental and control groups

\begin{tabular}{|c|c|c|c|c|c|c|}
\hline \multicolumn{2}{|c|}{ Variable } & $\begin{array}{l}\text { TBE. G } \\
(\mathrm{n}=30)\end{array}$ & $\begin{array}{l}\text { Cont. G } \\
(\mathrm{n}=31)\end{array}$ & \multirow[b]{2}{*}{0863} & $p$ & $\mathrm{~F}(p)$ \\
\hline \multirow[b]{2}{*}{ Depression } & wo & $38.46 \pm 3.46$ & $37.64 \pm 3.94$ & & .391 & \multirow{2}{*}{$\begin{array}{c}\text { Time } \\
33.219(<.001) \\
\text { Group } \\
34.957(<.001) \\
\mathrm{G}^{* \mathrm{~T}} \\
39.392(<.001)\end{array}$} \\
\hline & W12 & $\begin{array}{l}34.10 \pm 3.80 \\
28.83 \pm 2.74\end{array}$ & $\begin{array}{l}36.70 \pm 2.88 \\
37.70 \pm 3.68\end{array}$ & -10.653 & $<.001$ & \\
\hline
\end{tabular}

Exp. = experiment group; Cont. $=$ control group; $N R S=$ numeric rating scale $M=$ mean $; S D=$ standard deviation; $F(p)=$ repeated measures of ANOVA (Wilks's Lambda)

\subsection{Resistance exercise program effect on stress}

Stress was significantly different according to time as a result of repeated measurement and variance analysis of the scores measured three times for 12 weeks $(\mathrm{F}=54.16, \mathrm{p}<.001$ there was a significant difference over time $(F=88.22, p<.001)$, and there was a significant difference in the shoulder pain scores significant differences in scores between groups $(\mathrm{F}=$ $225.84, \mathrm{p}<.001)$. In addition, there was a significant difference in the interaction between group and time $(\mathrm{F}=112.06, \mathrm{p}<.001)$, and the partial eta squared, which is the effect of the resistance exercise program according to group and time, was 0.054 [Table 3].

Table 3 Comparison of stress between the experimental and control groups

\begin{tabular}{|c|c|c|c|c|c|c|}
\hline & & & & \multirow{3}{*}{$t$} & \multirow{3}{*}{$p$} & \multirow{3}{*}{$\mathrm{F}(\mathrm{p})$} \\
\hline \multirow{2}{*}{\multicolumn{2}{|c|}{ Variable }} & Exp. $(n=30)$ & Cont. $(\mathrm{n}=31)$ & & & \\
\hline & & Mean \pm SD & Mean $\pm \mathrm{SD}$ & & & \\
\hline \multirow{3}{*}{ Stress } & Pre-test & $36.50 \pm 3.45$ & $37.64 \pm 3.05$ & -1.035 & .304 & \multirow{3}{*}{$\begin{array}{c}\text { Time } \\
54.163(<.001) \\
\text { Group } \\
76.702(<.001) \\
\text { Group*Time } \\
194.379(<.001)\end{array}$} \\
\hline & & $31.70 \pm 3.90$ & $38.78 \pm 2.58$ & & $<.001$ & \\
\hline & Post-test 2 & $25.13 \pm 2.63$ & $38.70 \pm 2.39$ & -23.444 & $<.001$ & \\
\hline
\end{tabular}

Exp. $=$ experiment group $;$ Cont.$=$ control group $; N R S=$ numeric rating scale

$M=$ mean; $S D=$ standard deviation; $F(p)=$ repeated measures of ANOVA (Wilks's Lambda)

\subsection{Resistance exercise program effect on autonomic balance}

As a result of repeated measurement of the variance analysis of the parasympathetic nervous system using the Canopy 9 machine for a total of three times for 12 weeks, there was no significant difference over time. There was a significant difference in the activity between the two groups $(\mathrm{F}=.864, \mathrm{p}=.014)$. There was no significant difference in the interaction between group and time. In addition, the partial eta squared, which is the effect of the resistance exercise program according to the group and time, was 0.058 [Table 4].

The result of repeated measurement of the variance analysis of the sympathetic nervous system using the Canopy9 machine for a total of three times for 12 weeks showed no significant difference over time, and there was no significant difference in the activity 
between the two groups. In addition, there was no significant difference in the interaction between the groups and time [Table 4].

Table 4. Comparison of autonomic balance between the experimental and control groups

\begin{tabular}{|c|c|c|c|c|c|c|}
\hline \multirow{2}{*}{\multicolumn{2}{|c|}{ Variable }} & Exp. $(n=30)$ & Cont. $(n=31)$ & \multirow{3}{*}{$\begin{array}{c}t \\
.049\end{array}$} & \multirow{3}{*}{$\begin{array}{c}p \\
.961\end{array}$} & \multirow{5}{*}{$\begin{array}{c}\mathrm{F}(p) \\
\text { Time } \\
.110(.894) \\
\text { Group } \\
.864(.014) \\
\text { Group*Time } \\
\text { 3.645 (.058) }\end{array}$} \\
\hline & & Mean \pm SD & Mean \pm SD & & & \\
\hline \multirow{3}{*}{$\mathrm{HF}$} & Pre-test & $4.20 \pm 1.21$ & $4.18 \pm 0.80$ & & & \\
\hline & Post-test 1 & $4.49 \pm 0.87$ & $4.03 \pm 0.94$ & 1.965 & .054 & \\
\hline & Post-test 2 & $4.43 \pm 0.75$ & $4.09 \pm 1.11$ & 1.393 & .169 & \\
\hline \multirow{3}{*}{$\mathrm{LF}$} & Pre-test & $4.12 \pm 0.87$ & $4.08 \pm 1.00$ & 0.158 & .875 & $\begin{array}{c}\text { Time } \\
.314(.731)\end{array}$ \\
\hline & Post-test 1 & $4.18 \pm 0.54$ & $4.11 \pm 0.85$ & 0.399 & .691 & $\begin{array}{c}\text { Group } \\
.543(.569)\end{array}$ \\
\hline & Post-test 2 & $4.36 \pm 0.39$ & $4.06 \pm 0.87$ & 1.722 & .090 & $\begin{array}{c}\text { Group*Time } \\
1.164(.285)\end{array}$ \\
\hline
\end{tabular}

\section{Discussion}

This study attempted to confirm the effects on depression, stress, and autonomic balance in elderly who participated in a 12-week resistance exercise program. This study is a parallax experimental study before and after randomized control. The effects were analyzed in a total of 61 elderly subjects: 30 subjects were in the experimental group, and 31 subjects were in the control group. As a result, depression and stress were reduced, and the balance of the sympathetic and parasympathetic nervous systems of the autonomic nervous system was improved; In order to confirm the effect of this study's resistance exercise program subjectively and objectively, a questionnaire was used, and the stress index measurement and sympathetic nervous system and parasympathetic nervous system were measured.

As a result of the study, depression was significantly lower $(F=40.88, p<.001)$ in the experimental group who received resistance exercise for 12 weeks compared with the control group. The experimental group decreased $(\mathrm{F}=225.84, \mathrm{p}<.001)$ compared with the control group.

The results of depression and stress in the two groups were consistent with the results of a study of 679 diabetic elderly persons age 65 years or older who performed exercise in the Aging Research Panel [24]. In addition, depression decreased in elderly females who performed circular exercise including resistance exercise for 12 weeks, and a study that applied resistance exercise program to the upper and lower extremities for 12 weeks in the elderly showed improvement in depression and quality of life. In addition, as a result of a study that conducted complex exercise including resistance exercise for elderly diabetics for 16 weeks and a resistance exercise program for elderly diabetics for eight weeks, it was confirmed that stress was reduced and is consistent with this study. In this study, depression and stress in the experimental group significantly decreased six weeks after experimental treatment and continuously decreased until 12 weeks. Therefore, a resistance exercise program using an elastic band was very effective in reducing depression and stress in the elderly.

The elastic band resistance exercise program applied in this study was an exercise program developed in the preceding study [16] and is composed of movements that are not 
significantly affected by the location, and can be done conveniently to exercise various joints. Depression continuously decreased for six and 12 weeks, and the stress score also continuously decreased for six and 12 weeks. As a result, the muscle-strengthening elastic band resistance exercise program that concentrates on the upper limbs can be considered very effective, as depression and stress are reduced in six weeks through 70 minutes of exercise three times a week.

The balance of the autonomic nervous system is very important in maintaining and protecting the homeostasis of our body. This homeostasis helps the human body to be properly balanced in an ever-changing environment. This varies depending on gender, age, lifestyle, personality, genetic factors, and circadian rhythm. Also, the autonomic nervous system is affected by both exercising and not exercising. Exercise helps improve the ability of the autonomic nervous system to maintain homeostasis, and exercise helps improve homeostasis of the autonomic nervous system.

In order to confirm the effectiveness of the program, as a result of examining the autonomic balance score, the HF band after the experimental treatment was higher in the experimental group than in the control group, but it was not statistically significant. The LF band score was also higher in the experimental group than in the control group after 12 weeks of experimental treatment, but it was not statistically significant. However, as mentioned, the experimental group showed an increase in the sympathetic nervous system and the parasympathetic nervous system, and the control group showed a rather decreased value. This is in line with studies showing that regular exercise is effective in improving the autonomic nervous system function of the sympathetic and parasympathetic nervous systems and reducing the incidence of fatal cardiovascular diseases. In addition, the result of applying an exercise program, including resistance exercise for 12 weeks, to skinny women is consistent with this study. However, it has been reported that there is no improvement in heart rate variability after endurance exercise, that is, autonomic balance, and it is still difficult to draw a clear conclusion that exercise improves the autonomic nervous system. Therefore, as a limitation of this study, it is necessary to find a method to activate the sympathetic and parasympathetic nervous systems separately and analyze the results more systematically while checking the change of each variable. For this, it is considered that a method with high validity and high reliability is needed to measure the sympathetic nervous system and the parasympathetic nervous system, respectively. In this way, it is considered very important to use objective indicators to check the increase or decrease of each variable of the sympathetic and parasympathetic nerves in the study of the balance of the autonomic nervous system.

\section{Conclusion}

This study attempted to confirm the effects on depression, stress, and autonomic balance in elderly who participated in a 12-week resistance exercise program. From the results of the study, in the experimental group that applied the resistance exercise program using the elastic band for 12 weeks, depression and stress gradually decreased as time passed, and although not statistically significant, it was found that it also affected the improvement of autonomic balance. Therefore, resistance exercise using an elastic band is strongly recommended for elderly subjects to reduce depression and stress, and a follow-up study is suggested to measure the balance of the autonomic nervous system by dualizing it into sympathetic and parasympathetic nerves.

\section{References}


[1] Choi Soo Il, Lee Sang Mae, and Ko Jea Ug, "The task of elderly health policy analysis and policy for the women elderly health promotion," vol.15, no.1, pp.147-172, (2012)

[2] Davidson $\mathbf{J}$ and Turnbull CD, "Diagnostic significance of vegetative symptoms in depression,". $\mathrm{Br} \mathrm{J}$ Psychiatry, vol.4, no.148, pp.442-6, (1986)

[3] Lechin F, van der Dijs B, Orozco B, Lechin AE, Baez S, Lechin ME, and et al, "Plasma neurotransmitters, blood pressure, and heart rate during supine resting, orthostasis, and moderate exercise in dysthymic depressed patients," Biol Psychiatry, vol.37, no.12, pp.884-91, (1995)

[4] Tulen JH, Bruijn JA, de Man KJ, Pepplinkhuizen L, van den Meiracker AH, and Man in 't Veld AJ, "Cardiovascular variability in major depressive disorder and effects of imipramine or mirtazapine," J Clin Psychopharmacol, vol.16, no.2, pp. 135-45, (1996)

[5] “Heart rate variability: Standards of measurement, physiological interpretation, and clinical use," Task Force of the European Society of Cardiology and the North American Society of Pacing and Electrophysiology, Eur Heart J1.7, pp.354-381, (1996)

[6] Vernon H, "Schneider M: Chiropractic management of myofascial trigger points and myofascial pain syndrome: A systematic review of the literature," Journal of Manipulative and Physiological Therapeutics. Elsevier BV, vol.32, no.1, pp.14-24, (2009)

[7] Thayer JF, Yamamoto SS, and Brosschot, "JF: The relationship of autonomic imbalance, heart rate variability and cardiovascular disease risk factors," Int J Cardiol, vol.14, no.1, pp. 122-131, (2010)

[8] Kim Eun Kyung Lee, "Chang young: The Effects of aerobic exercise on cardiovascular autonomic neuropathy and coronary heart disease risk factors in sleep disordered breathing men," Exercise Science vol.18, no.2, pp. 391-400, (2009)

[9] Kim Seong Yeol, and Park Woo Kwun, "The effect of the elderly exercise program using elastic-band on the depression and physical self-efficacy of the elderly," Journal of Korean Society of Integrative Medicine, vol.7, no.4, pp. 53-59, (2019)

[10] Jung Il Gyu and Yoon Jin Hwan, "Human performance and exercise physiology," Seoul: Daekyung Books, (2011)

[11] Lee Sun Woo and Shin Sung Rae, "The effects of resistance exercise program for elders with type 2 diabetes on the selfcare, stress and HbA1c," Korean Journal of Adult Nursing, vol.20, no.3, pp.431-442, (2018)

[12] Kim Won Jong and Hur Myung Haeng, "Effect of Resistance Exercise Program for Middle-Aged Women with Myofascial Pain Syndrome on Shoulder Pain, Angle of Shoulder Range of Motion, and Body Composition Randomized Controlled Trial," RCT. Journal of Korean Academy of Nursing, vol.50, no.2, pp.286-97, (2020)

[13] Ehrman JK, deJong A, Sanderson B, Swain D, and et al., "Exercise test and prescription," Seoul: Hanmi Medicine, (2010)

[14] Im Wan ki., "Understanding the resistance movement," Seoul: Gwanglim Book House, (2007)

[15] Lenore Sawyer Radloff, "The CES-D Scale: A self-report depression scale for research in the general population,” Journal of Mathematical Psychology, vol.1, no.3, pp. 385-401, (1977)

[16] Chon KG, Choi SC, and Yang BC, "Integrated adaptation of CES-D in korea," The Korean Journal of Health Psychology, vol.6, no.1, pp. 59-76, (2001)

[17] Cohen J, "Eta-squared and partial eta-squared in fixed factor ANOVA designs," Educational and Psychological Measurement vol.33, no.1, pp. 107-112, (1973)

[18] Jung KH, "Influence of stress, social support and lifestyle on health-related quality of life for middle-aged women," Korean Society of Biological Nursing Science, vol.1, no.21, pp.62-69, (2019)

[19] Lee Sung Eun, "Regular exercise as a moderator of the relationship between illness-stress and depression," Mental Health \& Social Work 0.33, pp.167-192, (2009)

[20] Ha Soo Min, Kim Do Yeon, and Kim Ji Hyeon, "Effects of circuit exercise on functional fitness, estradiol, serotonin, depression and cognitive function in elderly women," Journal of Korean Association of Physical Education and Sport for Girls and Women, vol.31, no.3, pp. 199-217, (2017) 
[21] Davy KP, Miniclier NL, Taylor JA, Stevenson ET, and Seals DR, "Elevated heart rate variability in physically active postmenopausal women a cardioprotective effect Am J Physiol.," vol.271, no.2, pp. 455460, (1996)

[22] Woo Kyung Hee, Yang Jeong Ok, and Lee Joong Sook, "Effects of the upright body type exercise program on autonomic nervous system, balance, and vas in female middle school students," KINESIOLOGY, vol.16, no.2, pp.11-20, (2014)

[23] Leicht AS, Allen GD, and Hoey AJ, "Influence of intensive cycling training on heart rate variability during rest and exercise," Can J Appl Physiol., vol.28, no.6, pp. 898-909, (2003)

[24] Loimaala A, Huikuri H, Oja P, and Pasanen M. Vuori I., "Controlled 5-mo aerobic training improves heart rate but not heart rate variability or baroreflex sensitivity,” J Appl Physiol., vol.89, no.5, pp. 1825-1829, (2000) 